\title{
Implementasi Certainty Factor Untuk Diagnosa Penyakit Psoriasis
}

\author{
Putri Andriyani *, Zulfian Azmi**, Firahmi Rizky***, Ahmad Calam*** \\ *Sistem Informasi, STMIK Triguna Dharma \\ **Sistem Komputer STMIK Triguna Dharma \\ ***Sistem Informasi, STMIK Triguna Dharma
}

\begin{tabular}{l}
\hline Article Info \\
\hline Article history: \\
Received Jun $12^{\text {th }}, 2020$ \\
Revised Aug $20^{\text {th }}, 2020$ \\
Accepted Aug $26^{\text {th }}, 2020$ \\
\end{tabular}

\section{Keyword:}

Penyakit Psoriasis,

Sistem Pakar,

Metode Certainty Factor

\begin{abstract}
(10 pt)
Tanda klinis psoriasis selain penampakan dan distribusinya, ada tanda klinis khas pada psoriasis, yaitu fenomena tetesan lilin, tanda Auspitz, fenomena Koebner, serta rasa gatal dan nyeri yang bersifat lokal pada papul dan plak. Fenomena tetesan lilin terjadi ketika penggoresan skuama utuh dengan menggunakan pinggir gelas objek, lalu terjadi perubahan warna lebih putih menyerupai tetesan lilin. Tanda Auspitz adalah adanya darah yang keluar ketika lesi diangkat berupa pinpoint bleeding, sedangkan fenomena Koebner adalah lesi psoriasis yang diinduksi oleh adanya trauma pada kulit [2]. penyakit Psoriasis memiliki 8 jenis yaitu plak, kuku, kulit kepala, inversi, gutata, pustular, erotrodermik, artiris dan vulgaris. Kurangnya pengetahuan dan pemahaman terhadap penyakit psoriasis dan jenis - jenisnya menyebabkan seseorang lebih rentan terhadap beberapa penyakit tertentu, bahkan diantaranya cukup fatal seperti salah satunya kerusakan pada sendi sehingga kehilangan fungsinya dan dapat kelemahan.

Dalam permasalahan ini diperlukan sebuah sistem salah satunya adalah sistem pakar yang dapat mendiagnosa penyakit Psoriasis sehingga dapat dilakukan penanganan ataupun pencegahan yang tepat

Hasil penelitian merupakan terciptanya sebuah aplikasi Sistem Pakar dengan Metode Certainty Factor yang dapat membantu dapat mendiagnosa penyakit Psoriasis..
\end{abstract}

Copyright @ 2020 STMIK Triguna Dharma. All rights reserved.

\author{
Corresponding Author: * \\ Nama : Putri Andriyani \\ Program Studi : Sistem Informasi \\ STMIK Triguna Dharma \\ Email: pu3andriyani07@gmail.com
}

\section{PENDAHULUAN}

Penyakit Psoriasis banyak tersebar di seluruh dunia. Di Amerika Serikat terdapat 150.000 kasus baru psoriasis yang ditemukan, yaitu setara dengan hampir 2,2\% dari populasi Amerika Serikat, sedangkan data prevalensi psoriasis secara nasional di Indonesia masih belum diketahui Psoriasis terjadi pada pria dan wanita dari seluruh kelompok usia, etnis, dan semua negara. Diperkirakan 3\% penduduk dunia menderita psoriasis dengan perbandingan 1:1 pada pria dan wanita dewasa [1].

Psoriasis, peradangan kulit menahun, yang hingga kini belum ditemukan obatnya, dapat disembuhkan dengan cannabinoid, satu senyawa dari tanaman Cannabis/ganja. Pasien yang menderita penyakit ini biasanya menarik diri dari lingkungan, karena selalu berpotensi kambuh dan membuat penderita tidak percaya diri. Tanda klinis psoriasis selain penampakan dan distribusinya, ada tanda klinis khas pada psoriasis, yaitu fenomena tetesan lilin, tanda Auspitz, fenomena Koebner, serta rasa gatal dan nyeri yang bersifat lokal pada papul dan plak. Fenomena tetesan lilin terjadi ketika penggoresan skuama utuh dengan menggunakan pinggir gelas objek, lalu terjadi perubahan warna lebih putih menyerupai tetesan lilin. Tanda Auspitz adalah adanya darah yang keluar ketika lesi diangkat berupa pinpoint bleeding, sedangkan fenomena Koebner adalah lesi psoriasis yang diinduksi oleh adanya trauma pada kulit [2]. penyakit Psoriasis memiliki 8 jenis yaitu plak, kuku, kulit kepala, inversi, gutata, pustular, erotrodermik, artiris dan vulgaris. Kurangnya pengetahuan dan pemahaman terhadap penyakit psoriasis dan jenis - jenisnya menyebabkan seseorang lebih rentan terhadap beberapa penyakit tertentu, bahkan diantaranya cukup fatal seperti salah satunya kerusakan 
pada sendi sehingga kehilangan fungsinya dan dapat kelemahan. Dalam permasalahan ini diperlukan sebuah sistem salah satunya adalah sistem pakar yang dapat mendiagnosa penyakit Psoriasis sehingga dapat dilakukan penanganan ataupun pencegahan yang tepat.

Sistem pakar atau sering disebut dengan expert system merupakan cabang dari artificial intelligence atau kecerdasan buatan yang kinerjanya mengadopsi keahlian dari seorang pakar dan menyimpan pengetahuannya didalam komputer sehingga memungkinkan pengguna dapat berkonsultasi layaknya dengan pakar manusia. Sistem pakar ini dapat membantu mengetahui jenis Psoriasis dari gejala - gejala yang ditimbulkan dengan mengadopsi salah satu metode yaitu Certainty Factor. Karekteristik metode ini adalah merepresentasikan derajat kepercayaan suatu fakta atau aturan. Certainty Factor adalah suatu sistem yang mampu memecahkan ketidakpastian. [3]

\section{Kajian Pustaka}

\subsection{Sistem Pakar}

Aplikasi berbasis komputer yang banyak dipergunakan dalam penyelesaian permasalahan yang berkaitan dengan pemikiran ataupun keahlian seorang pakar disebut dengan Sistem pakar, yang mencoba dalam memecahkan masalah yang tidak dapat diselesaikan awam dan hanya bisa diselesaikan oleh seorang pakar dibidangnya, sistem pakar dikatakan berhasil jika mampu menghasilkan sebuah keputusan yang sama seperti yang dilakukan oleh pakar aslinya baik pada saat proses pengambilan keputusannya dan juga dari hasil keputusannya.

Mesin Inferensi adalah sebuah otak dari aplikasi sistem pakar. Dimana dalam mesin inferensi inilah kemampuan pakar ini disisipkan. Apa yang dikerjakan oleh mesin inferensi, didasarkan pada pengetahuanpengetahuan yang ada dalam basis pengetahuan yang telah diambil dari seorang pakar [4].

Istilah yang ada pada sistem pakar bersumber dari istilah knowledge-based expert system.Penyebab istilah ini muncul adalahuntuk memecahkan sebuah masalah yang jarang dapat diselesaikan oleh awam. [5].

Pengetahuan adalah informasi atau maklumat yang diketahui atau disadari oleh seseorang. Pengetahuan termasuk, tetapi tidak dibatasi pada deskripsi, hipotesis, konsep, teori, prinsip [6]

\subsection{Certainty Factor}

McAllister mangatakan Certainty Factor (Faktor Kepastian) adalah suatu metode untuk memastikan seberapa pasti kefaktaan yang diberikan dalam menggunakan sistem pakar. Certainty Factor diusulkan oleh Shortiffe dan Buchanan pada tahun 1975 untuk mengakomodasikan ketidakpastian pemikiran (inexact reasoning) seorang pakar. Faktor kepastian adalah ukuran pengamatan klinik dibuat oleh MYCIN dalam mempresentasikan tingkat kepercayaan[7],

1. Metode"Net Belief" yang diusulkan oleh E.H Shortliffe dan B.G Buchanan

$$
\begin{gathered}
C F(\text { rule })=M B(H, E)-M D(H, E) \\
M B(H, E)=\left\{\begin{array}{l}
\operatorname{Max}[P(H \mid E), P(H)]-P(H) \\
\operatorname{Max}[1,0]-P(H) \\
1
\end{array}\right. \\
M D(H, E)=\left\{\frac{\operatorname{Min}[P(H \mid E), P(H)]-P(H)}{\operatorname{Min}[1,0]-P(H)}\right.
\end{gathered}
$$

Dimana :

$$
\mathrm{CF} \text { (Rule) = factor kepastian }
$$

$\mathrm{MB}(\mathrm{H}, \mathrm{E})=$ measure of belief (ukuran kepercayaan) terhadap hipotesis $\mathrm{H}$, jika diberikan evidence $\mathrm{E}$ (antara 0 dan 1 )

$\mathrm{MD}(\mathrm{H}, \mathrm{E})=$ measure of disbelief, (ukuran ketidakpercayaan) terhadap evidence $\mathrm{H}$, jika diberikan evidence $\mathrm{E}$ (antara 0 dan 1 )

$\mathrm{P}(\mathrm{H})=$ probabilitas kebenaran hipotesis $\mathrm{H}$

$\mathrm{P}(\mathrm{H} \mid \mathrm{E})=$ probabilitas bahwa $\mathrm{H}$ benar karena fakta $\mathrm{E}$

\section{METODE PENELITIAN}

Metode Penelitian merupakan sebuah proses atau cara ilmiah dalam mendapatkan data yang akan digunakan untuk menyelesaikan masalah dengan dengan mengadakan studi langsung kelapangan untuk mengumpulkan data.

Variabel penelitian yang digunakan dalam penelitian ini adalah : 
1. Data Gejala Psoriasis

2. Data Penyakit Psoriasis

3. Data Basis Aturan untuk penyakit Psoriasis

\subsection{Algoritma Sistem}

Algoritma merupakan salah satu urutan langkah-langkah pendekatan yang dilakukan untuk membangun sebuah sistem pakar sehingga mendapat hasil yang diinginkan. Sistem pakar yang dibangun merupakan rule based expert system yang menggunakan metode Certainty Factor. Adapun langkah-langkah metode Certainty Factor antara lain :

1. Menentukan data Penyakit dan gejalanya.

2. Menentukan bobot gejala.

3. Proses inferensi.

4. Mengkombinasikan nilai Certainty Factor dari masing-masing kaidah

Bobot nilai pakar merupakan data yang diberikan langsung oleh pakar terhadap gejala-gejala yang mendasari suatu hipotesis dari pengidentifikasian penyakit Psoriasis. Berikut ini pengetahuan dasar atau informasi tentang gejala penyakit Psoriasis dari beserta nilai MB dan MD untuk setiap gejalanya. Bobot nilai gejala diperoleh dari rumus:

$$
\begin{gathered}
\mathrm{CF}[\mathrm{H}, \mathrm{E}]=\mathrm{MB}[\mathrm{H}, \mathrm{E}]-\mathrm{MD}[\mathrm{H}, \mathrm{E}] \\
\text { Cfcombine }=\mathrm{CF} 1+\mathrm{CF} 2 *(1-\mathrm{CF} 1)
\end{gathered}
$$

$\mathrm{MB}(\mathrm{h}, \mathrm{e})=$ Ukuran kepercayaan terhadap hipotesis h (antara 0 dan 1$)$

$\mathrm{MD}(\mathrm{h}, \mathrm{e})=$ Ukuran ketidakpercayaan terhadap hipotesish $(\operatorname{antara} 0$ dan 1$)$

$\mathrm{CF} \quad=$ Factor kepastian

\begin{tabular}{|c|c|c|c|c|}
\hline Nama Penyakit & Gejala & MB & MD & $\mathrm{CF}$ \\
\hline \multirow{8}{*}{$\begin{array}{c}\text { Psoriasis Vulgaris } \\
\text { (plak) }\end{array}$} & Timbulnya bintik merah & 0.76 & 0.22 & 0.54 \\
\hline & Timbulnya lesi merah yang melebar & 0.62 & 0.11 & 0.51 \\
\hline & Ditumbuhi sisik putih yang berlapis-lapis & 0.76 & 0.16 & 0.6 \\
\hline & Sering mengelupas & 0.81 & 0.18 & 0.63 \\
\hline & Gatal & 0.83 & 0.2 & 0.63 \\
\hline & Sakit dan perih & 0.78 & 0.13 & 0.65 \\
\hline & Sering tertutup lapisan putih keperakan & 0.8 & 0.12 & 0.68 \\
\hline & $\begin{array}{c}\text { Timbul di sekitar alis, lutut, kepala, siku dan } \\
\text { bagian belakang panggul }\end{array}$ & 0.65 & 0.21 & 0.44 \\
\hline \multirow{6}{*}{ Psoriasis Pustular } & Timbulnya lesi merah yang melebar & 0.75 & 0.1 & 0.65 \\
\hline & Ditumbuhi sisik putih yang berlapis-lapis & 0.63 & 0.3 & 0.33 \\
\hline & Gatal & 0.54 & 0.22 & 0.32 \\
\hline & Sering tertutup lapisan putih keperakan & 0.66 & 0.11 & 0.55 \\
\hline & Kulit tebal dan keras & 0.53 & 0.16 & 0.37 \\
\hline & Timbul pada bagian tangan dan kaki & 0.67 & 0.18 & 0.49 \\
\hline \multirow{6}{*}{$\begin{array}{c}\text { Psoriasis } \\
\text { Eritroderma }\end{array}$} & Timbulnya lesi merah yang melebar & 0.83 & 0.2 & 0.63 \\
\hline & Ditumbuhi sisik putih yang berlapis-lapis & 0.85 & 0.13 & 0.72 \\
\hline & Gatal & 0.8 & 0.22 & 0.58 \\
\hline & Sering tertutup lapisan putih keperakan & 0.65 & 0.21 & 0.44 \\
\hline & Kulit berwarna sangat merah & 0.76 & 0.21 & 0.55 \\
\hline & Kedinginan & 0.63 & 0 & 0.63 \\
\hline
\end{tabular}

Tabel 3.3 Jenis Penyakit Psoriasis beserta Nilai MB dan MD

Sumber dr. Zulilham. Spkk

Dalam pengujian analisa yang dilakukan, seseorang berkonsultasi mengenai penyakit Psoriasis, dari pilihan gejala yang diberikan kepada penderita yang mengalami 5 gejala antara lain adalah sebagai berikut: 
Tabel 3.4 gejala yang dialami

\begin{tabular}{|c|c|}
\hline No & Gejala \\
\hline 1 & Timbulnya lesi merah yang melebar \\
\hline 2 & Ditumbuhi sisik putih yang berlapis-lapis \\
\hline 3 & Gatal \\
\hline 4 & Sering tertutup lapisan putih keperakan \\
\hline
\end{tabular}

Berdasarkan data yang dialami, maka dapat dipecahkan permasalahan mengenai penyakit Psoriasis dengan menggunakan algoritma Certainty Factor yaitu sebagai berikut.

Tabel 3.5 Rule Penyakit Psoriasis

\begin{tabular}{|c|c|c|c|}
\hline Nama Penyakit & Gejala & $\mathrm{CF}$ & $\begin{array}{l}\text { Gejala } \\
\text { Pilihan }\end{array}$ \\
\hline \multirow{8}{*}{$\begin{array}{l}\text { Psoriasis Vulgaris } \\
\text { (plak) }\end{array}$} & Timbulnya bintik merah & 0.54 & \\
\hline & Timbulnya lesi merah yang melebar & 0.51 & $\mathrm{y}$ \\
\hline & Ditumbuhi sisik putih yang berlapis-lapis & 0.6 & $\mathrm{y}$ \\
\hline & Sering mengelupas & 0.63 & \\
\hline & Gatal & 0.63 & $\mathrm{y}$ \\
\hline & Sakit dan perih & 0.65 & \\
\hline & Sering tertutup lapisan putih keperakan & 0.68 & $\mathrm{y}$ \\
\hline & $\begin{array}{l}\text { Timbul di sekitar alis, lutut, kepala, siku dan } \\
\text { bagian belakang panggul }\end{array}$ & 0.44 & \\
\hline \multirow{6}{*}{$\begin{array}{l}\text { Psoriasis } \\
\text { Eritroderma }\end{array}$} & Timbulnya lesi merah yang melebar & 0.63 & $\mathrm{y}$ \\
\hline & Ditumbuhi sisik putih yang berlapis-lapis & 0.72 & $\mathrm{y}$ \\
\hline & Gatal & 0.58 & $\mathrm{y}$ \\
\hline & Sering tertutup lapisan putih keperakan & 0.44 & $\mathrm{y}$ \\
\hline & Kulit berwarna sangat merah & 0.55 & \\
\hline & Kedinginan & 0.63 & \\
\hline
\end{tabular}

Hasil menentukan CF combine untuk Penyakit Psoriasis Vulgaris (plak) adalah sebagai berikut : $\mathrm{CF}(\mathrm{h}, \mathrm{e})_{\mathrm{g} 1, \mathrm{~g} 2}=\quad \mathrm{CFgejala1}+\mathrm{CFgejala} 2 *(1-\mathrm{CF}$ ejalal $)$

$0.51+0.6 *(1-0.51)=0.804$

$$
\begin{aligned}
& \mathrm{CF}(\mathrm{h}, \mathrm{e})_{\mathrm{old} 1, \mathrm{~g} 3}=\quad \mathrm{CFold} 1+\mathrm{CF} \text { gejala } 3 *(1-\mathrm{CFold} 1) 0 \\
& 804+0.63 *(1-0.804)=0.92748 \\
& \mathrm{CF}(\mathrm{h}, \mathrm{e})_{\mathrm{old} 2, \mathrm{~g} 4}=\quad \mathrm{Cfold} 2+\mathrm{Cfgejala} 4 *(1-\mathrm{Cf} \text { old } 2) \\
& 0.92748+0.68 *(1-0.92748)= \\
& 0.9767936
\end{aligned}
$$

Hasil menentukan CF combine untuk Penyakit Psoriasis Eritroderma adalah sebagai berikut :

$$
\begin{aligned}
& \mathrm{CF}(\mathrm{h}, \mathrm{e})_{\mathrm{g} 1, \mathrm{~g} 2}=\mathrm{CFgejala1}+\mathrm{CFgejala} 2 *(1-\mathrm{CF} \text { ejalal }) \\
& 0.63+0.72 *(1-0.63)=0.8964 \\
& \mathrm{CF}(\mathrm{h}, \mathrm{e})_{\text {old } 1, \mathrm{~g} 3}=\quad \mathrm{CFold} 1+\mathrm{CF} \text { gejala } 3 *(1-\mathrm{CF} \text { old } 1) \\
& 0.8964+0.58 *(1-0.8964)= \\
& 0.956488
\end{aligned}
$$




$$
\begin{aligned}
\mathrm{CF}(\mathrm{h}, \mathrm{e})_{\mathrm{old} 2, \mathrm{~g} 4}=\quad & \text { Cfold } 2+\text { Cfgejala } 4 *(1-\text { Cfold } 2) \\
& 0.956488+0.48 *(1-0.956488)= \\
& 0.97563328
\end{aligned}
$$

Untuk Penyakit yang lainnya tidak dihitung dikarenakan tidak memiliki gejala yang terkait. Maka dari perhitungan dapat disimpulkan nilai CF untuk jenis pengidentifikasian Penyakit dari nilai CF terbesar adalah pada Vulgaris (plak) $=0.9767936$. Yaitu artinya adalah penderita tersebut mengalami Vulgaris (plak)

\section{Analisa Dan Hasil}

1. Form Diagnosa

Form diagnosa digunakan oleh pengunjung web. Pada form diagnosa ini pengunjung web diharuskan untuk memilih gejala-gejala sesuai dengan yang dialaminya. Berikut adalah form diagnosa.

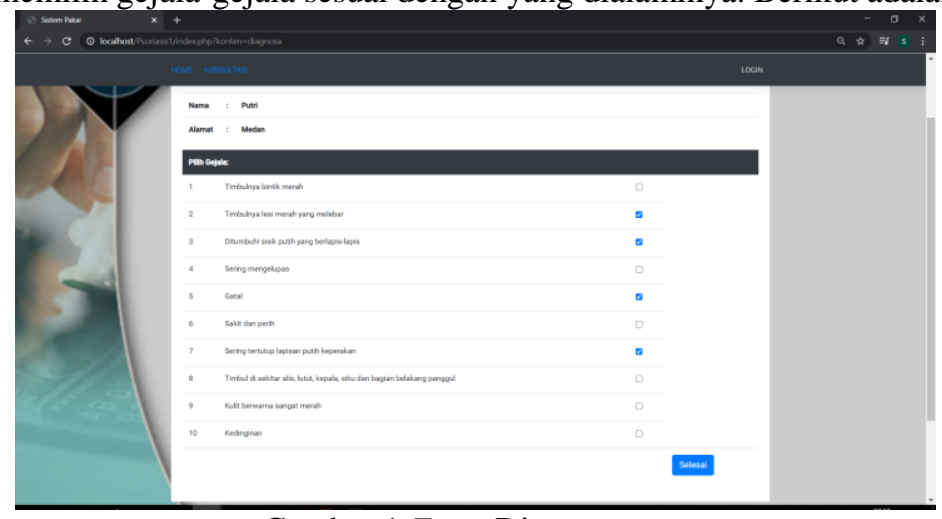

2. Form Hasil Diagnosa

Gambar 1 Form Diagnosa

Form Hasil Diagnosa ini merupakan form untuk menampilkan hasil Diagnosa berdasarkan gejala yang dipilih sebelumnya

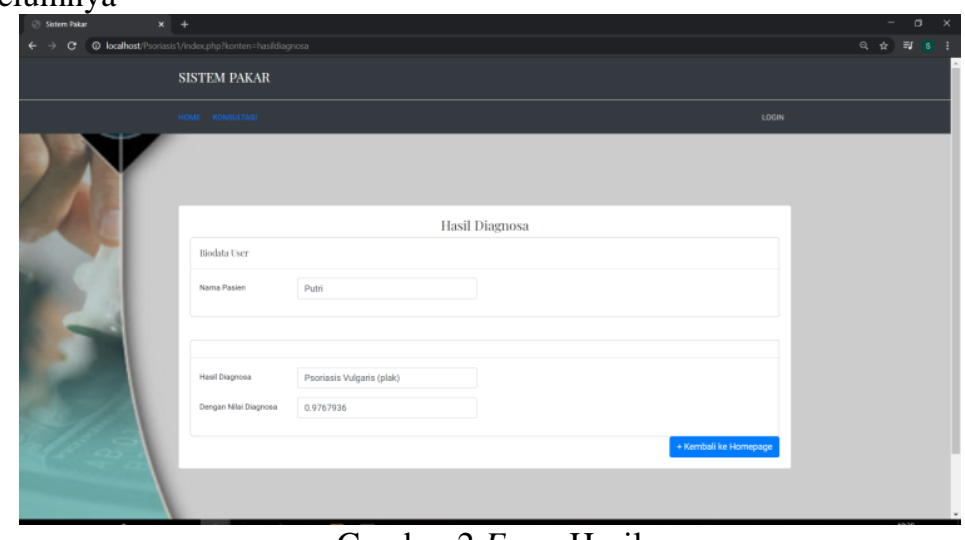

Gambar 2 Form Hasil

\section{Kesimpulan}

Berdasarkan analisa pada permasalahan yang terjadi dalam kasus yang diangkat tentang mendiagnosa penyakit psoriasis dengan menggunakan Metode Certainty Factor maka dapat ditarik kesimpulan sebagai berikut :

1. Berdasarkan hasil penelitian yang telah dilakukan, diketahui bahwa dalam mendiagnosa penyakit Psoriasis dengan metode Certainty Factor dilakukan dengan cara mengaitkan gejala-gejala yang terjadi dengan nilai kepercayaan dan ketidak percayaan seorang pakar kemudian mengkombinasikan semua gejala dengan kombinasi Certainty Factor.

2. Dalam merancang sistem pakar untuk mendiagnosa penyakit Psoriasis dengan metode Certainty Factor dilakukan dengan penelusuran ilmu pakar dengan runut maju dan melakukan pemodelan sistem dengan menggunakan pemodelan UML selanjutnya melakukan perancangan halaman web dalam sistem pakar yang dibangun. 
3. Untuk mengimplementasikan aplikasi sistem pakar dalam mendiagnosa penyakit Psoriasis menggunakan metode Certainty Factor, bisa dilakukan dengan cara menerapkan hasil jadi aplikasinya untuk digunakan oleh masyarakat luas kemudian membandingkan hasil seorang pakar dengan hasil yang dikeluarkan oleh sistem.

\section{REFERENSI}

[1] H. Santi and B. Andari, "Sistem Pakar Untuk Mengidentifikasi Jenis Kulit Wajah dengan Metode Certainty Factor," INTENSIF: Jurnal Ilmiah Penelitian dan Penerapan Teknologi Sistem Informasi, vol. 3, no. 2, p. 159, 172019.

[2] K. F. Aprilliana, "Psoriasis Vulgaris Pada Laki-laki 46 Tahun," J AgromedUnila, 2017.

[3] Azmi, Zulfian dan Verdi Yasin. 2017. Pengantar Sistem Pakar dan Metode. Jakarta: Mitra Wacana Media.

[4] Azmi, Z., \& Syahputra, K. (2018, Februari ). Implementasi Teorema Bayes Untuk Mendiagnosa Tingkat Stres. JISICOM (Journal of Information System, Informatics and Computing ), Vol.2 No.1 Februari 2018(ISSN : 2597-3673 (Online), ISSN : 2579-5201 (Printed)), 42-50.

[5] K. E. Setyaputri, A. Fadlil and D. Sunardi, "Analisis Metode Certainty Factor pada Sistem Pakar Diagnosa Penyakit THT".

[6] Suendri, "Implementasi Diagram UML (Unified Modelling Language) Pada Perancangan Sistem Informasi Remunerasi Dosen Dengan Database Oracle (Studi Kasus: UIN Sumatera Utara Medan)," ALGORITMA: Jurnal Ilmu Komputer dan Informatika, p. 1, 2018.

[7] Zulfian Azmi et al. 2018 Certainty Factor Perceptron Untuk Diagnosa Demam Berdarah Dengue (DBD)...Jurnal teknologi komunikasi dan informasi. Vo.7 no 1, Juni 2018: 47 -53 